\title{
Investigation of the chemical structures of laminar premixed flames fueled by
}

\section{acetaldehyde}

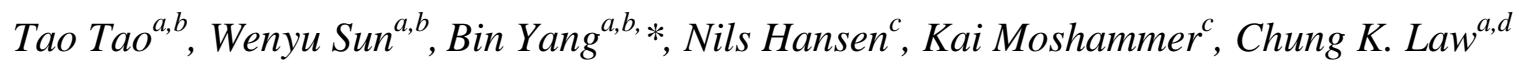 \\ ${ }^{a}$ Center for Combustion Energy and Department of Thermal Engineering, Tsinghua University, Beijing, 100084, $P$. \\ R. China \\ ${ }^{b}$ Key Laboratory for Thermal Science and Power Engineering of MOE, Tsinghua University, Beijing 100084, P. R. \\ China \\ ${ }^{c}$ Combustion Research Facility, Sandia National Laboratories, Livermore, CA 94551, U.S.A. \\ ${ }^{d}$ Department of Mechanical and Aerospace Engineering, Princeton University, Princeton, NJ 08544, U.S.A.
}

\section{Corresponding Author:}

Bin Yang

Center for Combustion Energy and Department of Thermal Engineering, Tsinghua University

Beijing 100084, P. R. China

Tel: +86-10-62796631

Fax: +86-10-62796631

E-mail: byang@tsinghua.edu.cn

\section{Colloquium: LAMINAR FLAME}

Word Count (Method 1): The total word count (exclusive of title page, abstract) is: $\mathbf{6 1 9 6}$ words

Main text: $\quad 2466$ words

References: $\quad \mathbf{6 4 7}$ words (35 references)

Tables: $\quad \mathbf{8 7 4}$ words (Table 1: 7 lines, 1 columns, 68 words; Table 2: 51 lines, 2 columns, 806 words)

Figures: $\quad \mathbf{2 2 0 9}$ words (7 figures with captions)

\begin{tabular}{ccccc}
\hline Figure & Column & Height/mm & Words in caption & Word Count \\
\hline 1 & double & 50.2 & 27 & 292 \\
2 & double & 55.6 & 19 & 308 \\
3 & double & 96.2 & 18 & 485 \\
4 & double & 42.4 & 30 & 261 \\
5 & double & 53.0 & 28 & 305 \\
6 & double & 48.8 & 19 & 278 \\
7 & double & 49.1 & 20 & 280 \\
\hline
\end{tabular}

* Corresponding author. E-mail: byang@ tsinghua.edu.cn, Tel: +86-10-62796631. 


\title{
Investigation of the chemical structures of laminar premixed flames fueled by acetaldehyde
}

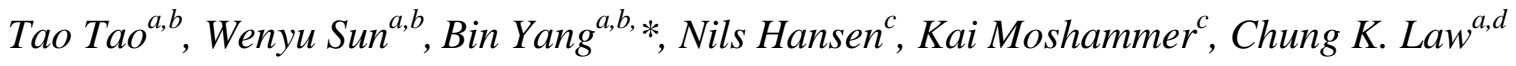 \\ ${ }^{a}$ Center for Combustion Energy and Department of Thermal Engineering, Tsinghua University, Beijing, 100084, $P$. \\ R. China \\ ${ }^{b}$ Key Laboratory for Thermal Science and Power Engineering of MOE, Tsinghua University, Beijing 100084, \\ China \\ ${ }^{c}$ Combustion Research Facility, Sandia National Laboratories, Livermore, CA 94551, United States \\ ${ }^{d}$ Department of Mechanical and Aerospace Engineering, Princeton University, Princeton, NJ 08544, United States
}

Abstract: Acetaldehyde is a key intermediate formed during the combustion of hydrocarbon and oxygenated fuels, and its role as an air pollution is concern-arousing. A better understanding of its combustion characteristics is of significance in developing core mechanisms and reducing the associated emissions. In this work, chemical structures of low-pressure laminar premixed acetaldehyde flames with equivalence ratios of 1.7 and 1.0 were measured by employing molecular-beam mass spectrometry with synchrotron vacuum ultraviolet light for ionization. Totally, about 40 species were identified and their mole fraction profiles are reported with well estimated uncertainty. To our knowledge, some oxygenated species, such as ethenol and butanal, were measured for the first time in acetaldehyde flames. Experimental species mole fraction profiles were compared with modeling results using several available kinetic mechanisms. These mechanisms well reproduce the mole fraction profiles of the major species and the $\mathrm{C}_{1} / \mathrm{C}_{2}$ hydrocarbon intermediates, however, their unsatisfactory predictive capability for some fuel-related oxygenated intermediates,

* Corresponding author. E-mail: byang@ tsinghua.edu.cn, Tel: +86-10-62796631. 
such as $\mathrm{C}_{2} \mathrm{H}_{3} \mathrm{O}$ isomers, suggests that the acetaldehyde sub-mechanism needs further investigation. Our experimental results provide valuable information for future mechanism development.

Keywords: Acetaldehyde; Laminar premixed flames; Photoionization mass spectrometry; Flame intermediates. 


\section{Introduction}

Acetaldehyde $\left(\mathrm{CH}_{3} \mathrm{CHO}\right)$ is an important flame intermediate and a toxic emission species in hydrocarbon fuels and biofuels combustion, especially for the alcohol biofuels which are widely used[1, 2]. Understanding of acetaldehyde combustion is essential in the construction of the alcohol combustion mechanism and $\mathrm{C} 0-\mathrm{C} 4$ core mechanisms, which serve as base mechanisms for large fuels.

Kern et al. [3] and Gupte et al. [4] studied the thermal decomposition of acetaldehyde in a shock tube (ST) and developed their mechanisms. Also, using a shock tube, Won et al. [5] measured the ignition delay of acetaldehyde and proposed a mechanism consisting of 34 species and 110 reactions. Both pyrolysis and oxidation were investigated by Yasunaga et al. [6] in three different shock tubes connected to laser/UV absorption or IR-emission equipment, which provided the concentration variations of hydrocarbon compounds and ketene during the reaction. In addition to the shock tube experiments, the unstretched laminar burning velocities of acetaldehyde/air flame at different equivalence ratios and initial temperatures were reported by Christensen et al. [7]. Experiments in a jet-stirred reactor (JSR) were conducted by Dagaut et al. [8], employing offline gas chromatography (GC) to measure the concentrations of some intermediates. The structures of a low-pressure premixed flame of acetaldehyde were measured at three different equivalence ratios using an electron ionization mass spectrometer (EIMS) by Leplat et al. [9]. Based on their experimental results, a mechanism was developed through an optimization of Marinov's ethanol mechanism [10]. However, mole fraction profiles for only five major intermediates, i.e., $\mathrm{CH}_{2} \mathrm{O}, \mathrm{C}_{2} \mathrm{H}_{2}, \mathrm{C}_{2} \mathrm{H}_{4}, \mathrm{CH}_{3}$, $\mathrm{CH}_{4}$, were observed and used to test the model. 
The main purpose of this work is to provide more detailed information on the chemistry of acetaldehyde combustion. The structures of two low-pressure premixed flames were measured by molecular-beam mass spectrometry (MBMS) using synchrotron VUV radiation as the ionization source. About 40 species were identified and quantified in the experiments. Three existing kinetic models, including AramcoMech1.3 [11], USC Mech II [12], and the mechanism of Leplat et al. [9], were tested and compared to provide guidance for the future development of an acetaldehyde sub-mechanism.

\section{Experimental details}

In the present study, two acetaldehyde flames were investigated. Detailed flame conditions are shown in Table 1. The pressures were chosen to gain a stable flame with appropriate flame thickness. The acetaldehyde vapor was generated by keeping a stainless steel bottle filled with liquid acetaldehyde in a room-temperature water bath. Since the saturated vapor pressure of acetaldehyde is $100.85 \mathrm{kPa}$ at $293 \mathrm{~K}$, the vapor pressure in the bottle was higher than atmospheric pressure and hence the pure acetaldehyde vapor could form a continuous flow.

\section{Table 1}

Experimental conditions of two acetaldehyde flames.

\begin{tabular}{ccccccc}
\hline \multirow{2}{*}{ Flame } & \multirow{2}{*}{ Equivalence ratio } & \multirow{2}{*}{$\begin{array}{c}\text { Pressure } \\
\text { (Torr) }\end{array}$} & $\mathrm{CH}_{3} \mathrm{CHO}$ & $\mathrm{O}_{2}$ & $\mathrm{Ar}$ & Total \\
\cline { 4 - 7 } & 1.70 & 30.0 & 0.810 & 1.190 & 2.000 & 4.0 \\
2 & 1.00 & 15.0 & 0.571 & 1.429 & 2.000 & 4.0 \\
\hline
\end{tabular}

${ }^{\text {a }}$ Standard liter per minute

Experiments were conducted in the Advanced Light Source (ALS) of the Lawrence Berkeley National Laboratory (LBNL), employing a flame-sampling photoionization molecular-beam mass spectrometer (PI-MBMS) [13, 14]. Low pressure premixed flames were stabilized on the surface of a 
stainless steel McKenna type burner of $60 \mathrm{~mm}$ diameter. Flame gases were sampled along the axis with a $0.4 \mathrm{~mm}$ orifice of a quartz nozzle, forming a molecular beam, which was subsequently ionized by the tunable vacuum-ultraviolet (VUV) synchrotron radiation. The ionized species were collected and analyzed using a high resolution time-of-flight (TOF) mass spectrometer. Two experimental modes are adopted. Firstly, with the nozzle fixed at several millimeters from the burner surface, the photon energy is scanned to get a photoionization efficiency (PIE) curve for species identification [15]. The other operation mode involves changes the distance between nozzle and burner surface with several different fixed photon energies (Fig. S1), producing the species concentration profiles along the axis as described in Ref. [16]. Results of the peak mole fractions and the corresponding positions in the flame are listed in Table 2, along with the ionization energy data, the photon energy and photoionization cross-sections (PICS) used for quantification, and the reference for PICS. Temperature profiles were determined based on the relationship between flame temperature and the pressure in the first-stage chamber $[17,18]$. The exhaust gas temperature, used as a reference temperature here, was measured using laser-induced fluorescence (LIF) of the $\mathrm{OH}$ radical as described in Ref. [19]. The uncertainty of the temperature was estimated to be $\pm 150 \mathrm{~K}$. This uncertainty would not significantly alter the mechanistic conclusions including the reaction pathway analysis, as discussed by Dooley et al. [20]. To validate this conclusion, two additional computations were performed for the fuel-rich flame with perturbed temperature profiles. The exhaust gas temperature was increased and decreased by $150 \mathrm{~K}$ separately, producing a $300 \mathrm{~K}$ difference, and the temperature profiles were changed proportionally based on the relationship between flame temperature and the pressure in the first-stage chamber. Model predictions with the perturbed temperature profiles for major species and some selected species are shown in Fig1. Detailed results 
are presented in the Supplemental Fig. S2. Detailed mole fraction profiles and the temperature profiles are also provided in the Supplemental Material. 


\section{Table 2}

List of intermediates measured in the two flames. M: Relative molecular mass; IE: ionization energy;

E: photon energy used for quantification; $\operatorname{PICS}(\mathrm{E})$ : photoionization cross section and references;

DFB: distance from the burner for the maximum; $\mathrm{x}_{\max }$ : peak mole fraction; UF: uncertainty factor of the peak mole fraction.

\begin{tabular}{|c|c|c|c|c|c|c|c|c|c|c|c|}
\hline \multirow{2}{*}{ M } & \multirow{2}{*}{ Formula } & \multirow{2}{*}{ Species } & \multirow{2}{*}{$\begin{array}{l}I E \\
\mathrm{eV}\end{array}$} & \multirow{2}{*}{$\begin{array}{c}E \\
\mathrm{eV}\end{array}$} & \multicolumn{2}{|c|}{$\operatorname{PICS(\mathrm {E})}$} & \multicolumn{2}{|c|}{ Phi $=1.7$} & \multicolumn{2}{|c|}{$\mathrm{Phi}=1.0$} & \multirow{2}{*}{ UF } \\
\hline & & & & & $\mathrm{Mb}^{\mathrm{a}}$ & Refer. & DFB & $x_{\max }$ & DFB & $x_{\max }$ & \\
\hline 15 & $\mathrm{CH}_{3}$ & Methyl & 9.84 & 10.0 & 4.78 & {$[21]$} & 4.75 & $9.05 \times 10^{-3}$ & 3.70 & $9.80 \times 10^{-3}$ & 1.8 \\
\hline 16 & $\mathrm{CH}_{4}$ & Methane & 12.61 & 13.2 & 4.72 & [22] & 2.25 & $1.83 \times 10^{-2}$ & 1.20 & $1.03 \times 10^{-2}$ & 1.5 \\
\hline 26 & $\mathrm{C}_{2} \mathrm{H}_{2}$ & Acetylene & 11.40 & 13.2 & 39.10 & [23] & 5.00 & $5.67 \times 10^{-3}$ & 4.20 & $1.46 \times 10^{-3}$ & 1.5 \\
\hline 28 & $\mathrm{C}_{2} \mathrm{H}_{4}$ & Ethylene & 10.51 & 11.5 & 8.02 & [23] & 4.75 & $7.97 \times 10^{-3}$ & 3.70 & $4.34 \times 10^{-3}$ & 1.5 \\
\hline \multirow[t]{2}{*}{29} & $\mathrm{CHO}$ & Formyl & 8.12 & 9.8 & 1.46 & $\mathrm{a}$ & 5.50 & $4.89 \times 10^{-5}$ & 4.20 & $6.53 \times 10^{-5}$ & 2.5 \\
\hline & $\mathrm{C}_{2} \mathrm{H}_{5}$ & Ethyl & 8.12 & 10.0 & 5.49 & [24] & 4.50 & $1.90 \times 10^{-4}$ & 3.45 & $6.13 \times 10^{-3}$ & 2.0 \\
\hline \multirow[t]{2}{*}{30} & $\mathrm{CH}_{2} \mathrm{O}$ & Formaldehyde & 10.88 & 11.5 & 10.13 & [25] & 4.25 & $5.53 \times 10^{-3}$ & 3.45 & $7.91 \times 10^{-3}$ & 1.8 \\
\hline & $\mathrm{C}_{2} \mathrm{H}_{6}$ & Ethane & 11.52 & 12.3 & 15.25 & $\mathrm{~b}$ & 4.00 & $6.93 \times 10^{-3}$ & 3.20 & $6.13 \times 10^{-3}$ & 1.5 \\
\hline 31 & $\mathrm{CH}_{3} \mathrm{O}$ & Methoxy & 10.72 & 11.0 & 6.43 & $\mathrm{c}$ & 4.25 & $2.31 \times 10^{-5}$ & 3.95 & $1.52 \times 10^{-5}$ & 3.0 \\
\hline 32 & $\mathrm{CH}_{4} \mathrm{O}$ & Methanol & 10.84 & 11.0 & 3.63 & [23] & 3.00 & $6.06 \times 10^{-4}$ & 1.95 & $5.87 \times 10^{-4}$ & 1.5 \\
\hline \multirow[t]{2}{*}{40} & $\mathrm{C}_{3} \mathrm{H}_{4}$ & Allene & 9.69 & 10.3 & 15.39 & {$[26]$} & 5.00 & $4.97 \times 10^{-5}$ & 4.20 & $1.59 \times 10^{-5}$ & 1.5 \\
\hline & & Propene & 10.36 & 11.0 & 43.47 & [26] & 4.75 & $8.62 \times 10^{-5}$ & 4.20 & $2.46 \times 10^{-5}$ & 1.5 \\
\hline \multirow[t]{2}{*}{42} & $\mathrm{C}_{2} \mathrm{H}_{2} \mathrm{O}$ & Ketene & 9.62 & 11.5 & 13.01 & [27] & 4.50 & $9.21 \times 10^{-4}$ & 3.45 & $8.52 \times 10^{-4}$ & 1.5 \\
\hline & $\mathrm{C}_{3} \mathrm{H}_{6}$ & Propene & 9.73 & 10.5 & 11.09 & [26] & 4.50 & $1.92 \times 10^{-4}$ & 3.45 & $1.07 \times 10^{-4}$ & 1.3 \\
\hline \multirow[t]{2}{*}{43} & $\mathrm{C}_{2} \mathrm{H}_{3} \mathrm{O}$ & Acetyl & 9.55 & 10.0 & 5 & $\mathrm{~d}$ & 4.00 & $2.60 \times 10^{-5}$ & 3.45 & $1.10 \times 10^{-4}$ & 5.0 \\
\hline & & Vinyloxy & 10.10 & 10.5 & 10 & $\mathrm{~d}$ & 2.00 & $2.46 \times 10^{-4}$ & 2.70 & $3.45 \times 10^{-4}$ & 5.0 \\
\hline 44 & $\mathrm{C}_{2} \mathrm{H}_{4} \mathrm{O}$ & Ethenol & 9.33 & 9.8 & 4.29 & [26] & 4.00 & $5.68 \times 10^{-4}$ & 3.45 & $2.12 \times 10^{-4}$ & 1.5 \\
\hline \multirow[t]{3}{*}{46} & $\mathrm{C}_{2} \mathrm{H}_{6} \mathrm{O}$ & Dimethylether & 10.03 & 10.3 & 6.78 & [23] & 0.50 & $5.59 \times 10^{-4}$ & 2.70 & $4.52 \times 10^{-4}$ & 1.5 \\
\hline & & Ethanol & 10.48 & 11.0 & 4.88 & [23] & 2.75 & $1.93 \times 10^{-4}$ & 1.45 & $9.91 \times 10^{-5}$ & 1.5 \\
\hline & $\mathrm{CH}_{2} \mathrm{O}_{2}$ & Formic acid & 11.33 & 11.5 & 5.04 & [23] & 1.50 & $1.14 \times 10^{-4}$ & 2.20 & $1.41 \times 10^{-4}$ & 1.5 \\
\hline 50 & $\mathrm{C}_{4} \mathrm{H}_{2}$ & Diacetylene & 10.17 & 10.5 & 23.82 & [23] & 5.50 & $7.83 \times 10^{-5}$ & - & - & 1.5 \\
\hline 52 & $\mathrm{C}_{4} \mathrm{H}_{4}$ & Vinylacetylene & 9.58 & 11.0 & 37.61 & [23] & 4.75 & $4.64 \times 10^{-5}$ & 4.20 & $6.38 \times 10^{-6}$ & 1.5 \\
\hline \multirow[t]{3}{*}{54} & $\mathrm{C}_{4} \mathrm{H}_{6}$ & 1,3-Butadiene & 9.07 & 9.5 & 10.33 & [23] & 4.50 & $2.95 \times 10^{-5}$ & 3.70 & $6.34 \times 10^{-6}$ & 1.5 \\
\hline & & 2-Butyne & 9.58 & 10.0 & 14.56 & $\mathrm{~b}$ & 3.75 & $5.98 \times 10^{-6}$ & 3.95 & $6.37 \times 10^{-6}$ & 2.0 \\
\hline & & 1-Butyne & 10.18 & 10.3 & 12.05 & [22] & 4.25 & $1.96 \times 10^{-5}$ & 3.45 & $1.03 \times 10^{-5}$ & 2.5 \\
\hline \multirow[t]{2}{*}{56} & $\mathrm{C}_{3} \mathrm{H}_{4} \mathrm{O}$ & Methylketene & 9.0 & 9.5 & 8.49 & $\mathrm{~d}$ & 4.25 & $4.00 \times 10^{-5}$ & 3.45 & $4.49 \times 10^{-5}$ & 2.5 \\
\hline & $\mathrm{C}_{4} \mathrm{H}_{8}$ & $\mathrm{f}$ & - & 10.5 & 10 & e & 4.25 & $4.18 \times 10^{-5}$ & 3.70 & $1.40 \times 10^{-5}$ & 3.0 \\
\hline \multirow[t]{2}{*}{58} & $\mathrm{C}_{3} \mathrm{H}_{6} \mathrm{O}$ & Acetone & 9.70 & 9.8 & 5.50 & [23] & 4.25 & $3.14 \times 10^{-4}$ & 2.70 & $1.04 \times 10^{-3}$ & 1.5 \\
\hline & & Propanal & 9.96 & 10.5 & 11.22 & [22] & 4.00 & $6.44 \times 10^{-4}$ & 3.20 & $6.32 \times 10^{-4}$ & 1.5 \\
\hline 59 & $\mathrm{C}_{3} \mathrm{H}_{7} \mathrm{O}$ & $\mathrm{f}$ & - & 10.0 & 10 & $\mathrm{~d}$ & 4.00 & $2.38 \times 10^{-5}$ & 2.70 & $5.44 \times 10^{-5}$ & 3.0 \\
\hline 60 & $\mathrm{C}_{2} \mathrm{H}_{4} \mathrm{O}_{2}$ & Acetic acid & 10.64 & 11.5 & 10 & $\mathrm{~d}$ & 1.50 & $4.97 \times 10^{-5}$ & 2.00 & $1.21 \times 10^{-4}$ & 3.0 \\
\hline 64 & $\mathrm{C}_{5} \mathrm{H}_{4}$ & 1,3-Pentadiyne & 9.5 & 10.0 & 33.22 & {$[28]$} & 5.00 & $1.81 \times 10^{-6}$ & - & - & 2.5 \\
\hline
\end{tabular}




\begin{tabular}{|c|c|c|c|c|c|c|c|c|c|c|c|}
\hline 68 & $\mathrm{C}_{4} \mathrm{H}_{4} \mathrm{O}$ & Furan & 8.88 & 10.0 & 11.14 & [27] & 0.25 & $9.29 \times 10^{-6}$ & 0.95 & $1.46 \times 10^{-5}$ & 2.5 \\
\hline 70 & $\mathrm{C}_{4} \mathrm{H}_{6} \mathrm{O}$ & $\begin{array}{l}\text { Methyl vinyl } \\
\text { Ketene }\end{array}$ & 9.65 & 10.3 & 11.26 & [27] & 1.00 & $8.95 \times 10^{-6}$ & 0.00 & $1.24 \times 10^{-5}$ & 2.5 \\
\hline \multirow[t]{2}{*}{72} & $\mathrm{C}_{4} \mathrm{H}_{8} \mathrm{O}$ & Tetrahydrofuran & 9.4 & 9.8 & 4.39 & {$[22]$} & 4.00 & $2.09 \times 10^{-5}$ & 3.45 & $8.25 \times 10^{-5}$ & 2.5 \\
\hline & & Butanal & 9.82 & 10.5 & 9.02 & [27] & 4.00 & $1.24 \times 10^{-5}$ & 2.70 & $1.17 \times 10^{-5}$ & 2.5 \\
\hline 74 & $\mathrm{C}_{4} \mathrm{H}_{10} \mathrm{O}$ & 1-Butanol & 9.99 & 11.0 & 0.77 & [29] & - & - & 2.70 & $3.00 \times 10^{-4}$ & 2.5 \\
\hline
\end{tabular}

$\mathrm{a}: \mathrm{Mb}$ is the unit for photoionization cross-sections (PICS). $1 \mathrm{Mb}=10-18 \mathrm{~cm} 2$.

b: PICS was estimated based on PIE curve gained in present study.

c: ALS unpublished data.

d: PICS was estimated based on previous PIE curve.

e: PICS was estimated based on our experience.

f: PICS was estimated based on all possible species' PICS.

$\mathrm{g}$ : The structures of isomers cannot be identified unambiguously. 

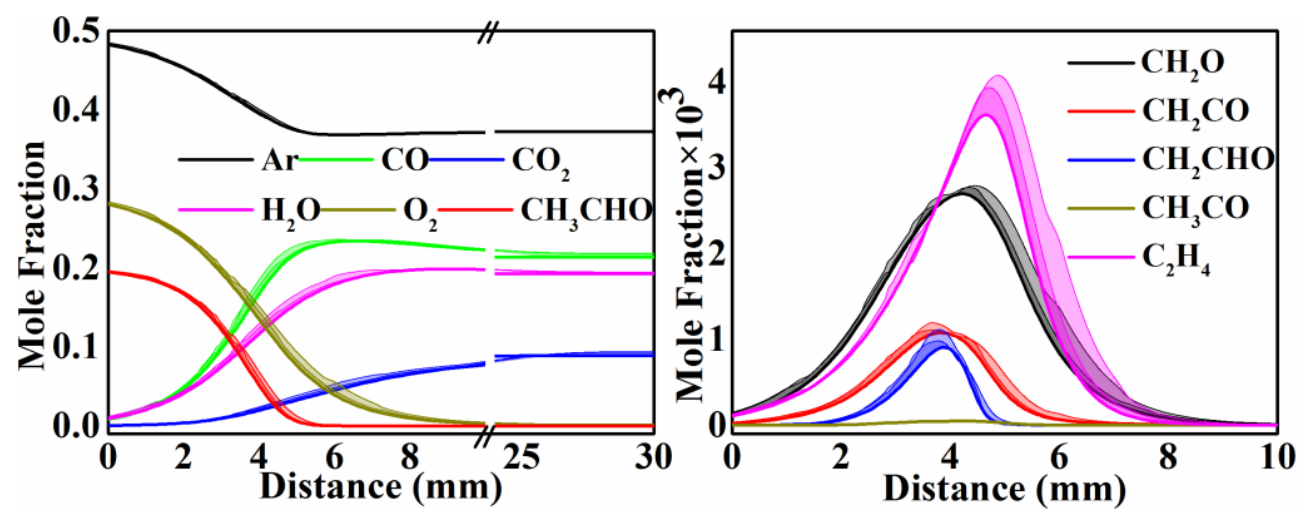

Fig. 1. Model predictions using AramcoMech1.3 with the perturbed temperature profiles $( \pm 150 \mathrm{~K})$ in fuel-rich acetaldehyde flame. Filled areas represent effect of temperature uncertainties on modeling computations.

The mole fraction profiles are affected by numerous parameters with uncertainties, such as the precision of photon energy, the sensitivity of ion detector, the quenching of radicals caused by their interaction with nozzle, the uncertainty of referenced PICS data, and the uncertainty propagation through the quantification procedure (Fig. S1); among which the uncertainty of PICS data usually takes a dominant place. For those minor species with no experimental PICSs, the PICS values were estimated at demanded energy, which introduces uncertainties with factors of 2-3. To be specific here, the uncertainty factor (UF) of A means that the upper limit is AxUF and the lower limit is A/UF. While for those having experimental PICSs, the uncertainty factors vary between 1.3-1.5, depending on the accuracy of the PICS data and the consistency between the PICS of target species and reference species. As illustrated in the literature [16], the conversion from original signal data to mole fraction profiles is a hierarchical process. In this approach, a species with a known concentration is used as a reference to deduce the mole fraction profiles of the target species. It is believed that the uncertainty will not completely propagate through the quantification procedure, because the mole fraction is deduced hierarchically in the form of proportion, which will eliminate some intrinsic errors in PICS measurements. Another vital cause of inaccuracy is the quenching of 
radicals caused by the collision between species and the aperture wall of nozzle, and the recombination of radicals on probe surface. This effect will bring in an uncertainty factor ranging from 1.3 [30] to 2 [31] or even higher, depending on the species molecular structure. Since the relationship between uncertainty factor and these various effects is not clear enough to be expressed in a formula, uncertainty factors can only be estimated for each species based on the above discussion, which is shown in Table 2. Concentration profiles at the first 1 millimeter are less reliable due to sampling disturbance and therefore are not shown in the following figures.

\section{Modeling description}

All simulations were performed with the Chemkin Pro Software [32], with mixture-averaged transport and thermal diffusion included. Three existing mechanisms were adopted to reproduce our experimental results, i.e. AramcoMech1.3 [11], USC Mech II [12], and the mechanism from Leplat et al. [9], which will be abbreviated as NUI, USC and Leplat hereafter. The newly-updated NUI could be a base for the development of acetaldehyde mechanism, because it has already been validated against some experimental results of acetaldehyde in ST and JSR. USC, another widely used core mechanism, and Leplat, a mechanism aimed at acetaldehyde combustion, will give valuable information from their own perspectives. In the present work, we do not intend to propose a new mechanism based on our experimental results, because that the acetaldehyde sub-mechanism is closely tied with the core mechanisms. In fact, while it is beyond the scope of this study to update the related reaction in core mechanisms, the information provided by our experimental results and their comparisons with predictions by different mechanisms are expected to contribute to further development of core mechanisms.

\section{Results and discussion}


In our experiments, in addition to the six major species ( $\mathrm{Ar}, \mathrm{CO}, \mathrm{CO}_{2}, \mathrm{H}_{2} \mathrm{O}, \mathrm{CH}_{3} \mathrm{CHO}$ and $\mathrm{O}_{2}$ ), about 40 intermediate species were identified and quantified. Similar to Leplat's work [9], $\mathrm{C}_{1} / \mathrm{C}_{2}$ hydrocarbons are abundant in acetaldehyde flames, whose concentrations could reach $1.0 \times 10^{-2}$. Besides, $\mathrm{C}_{3} / \mathrm{C}_{4}$ hydrocarbons are also non-negligible in the flames. Many oxygenated intermediates are identified and quantified in the present work, which are of great value for the development of an acetaldehyde sub-mechanism, because these oxygenates are closely related to the fuel reactions. For example, the $\mathrm{C}_{1} / \mathrm{C}_{2}$ oxygenates, such as $\mathrm{CHO}, \mathrm{C}_{2} \mathrm{H}_{3} \mathrm{O}$, may result from fuel decomposition, and some $\mathrm{C}_{3} / \mathrm{C}_{4}$ oxygenates, such as $\mathrm{CH}_{3} \mathrm{COCH}_{3}$, are likely produced by the recombination of radicals. This section will discuss the importance of the concentration profiles of these species in the development of an acetaldehyde sub-mechanism.

Experimental and modeling mole fraction profiles of the major species in the two flames are shown in Fig. 2. Since all three models do a comparable job in predicting major species fractions, only the predictions of NUI are presented to avoid cluttering.
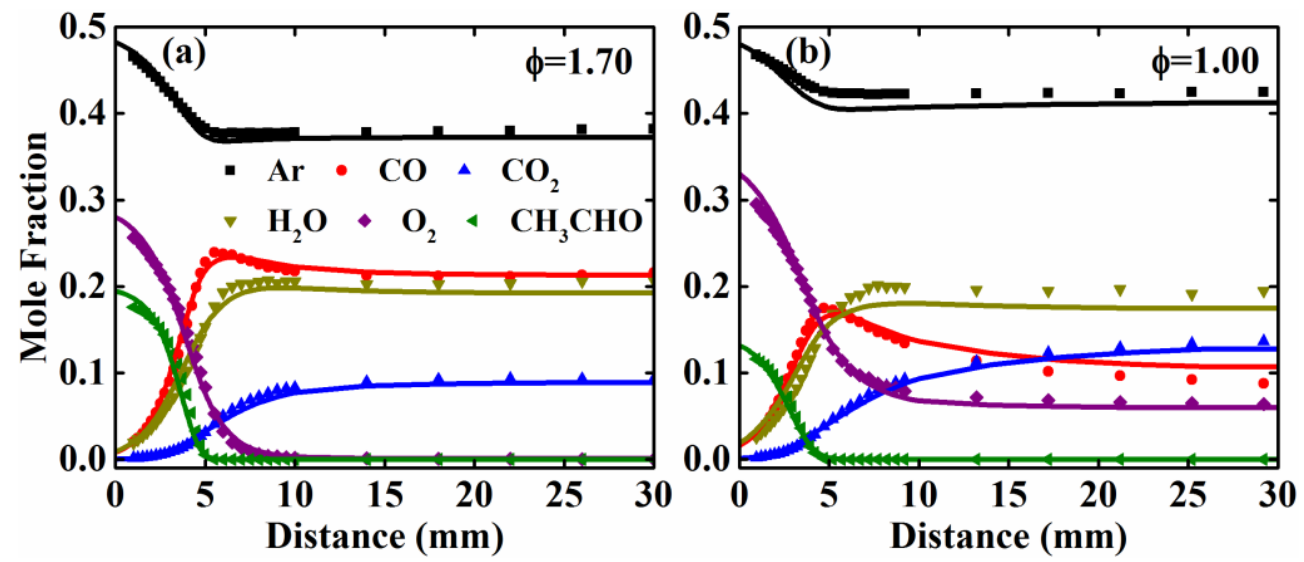

Fig. 2. Measured mole fraction profiles (symbols) of major species in two flames, compared with predictions from NUI (lines).

Figure 3 shows that besides the major species mole fractions, small hydrocarbons are also well captured in the two flames by the three models. This observation is not surprising because the 
mechanisms have been validated against the experimental data of small hydrocarbons over a wide range.

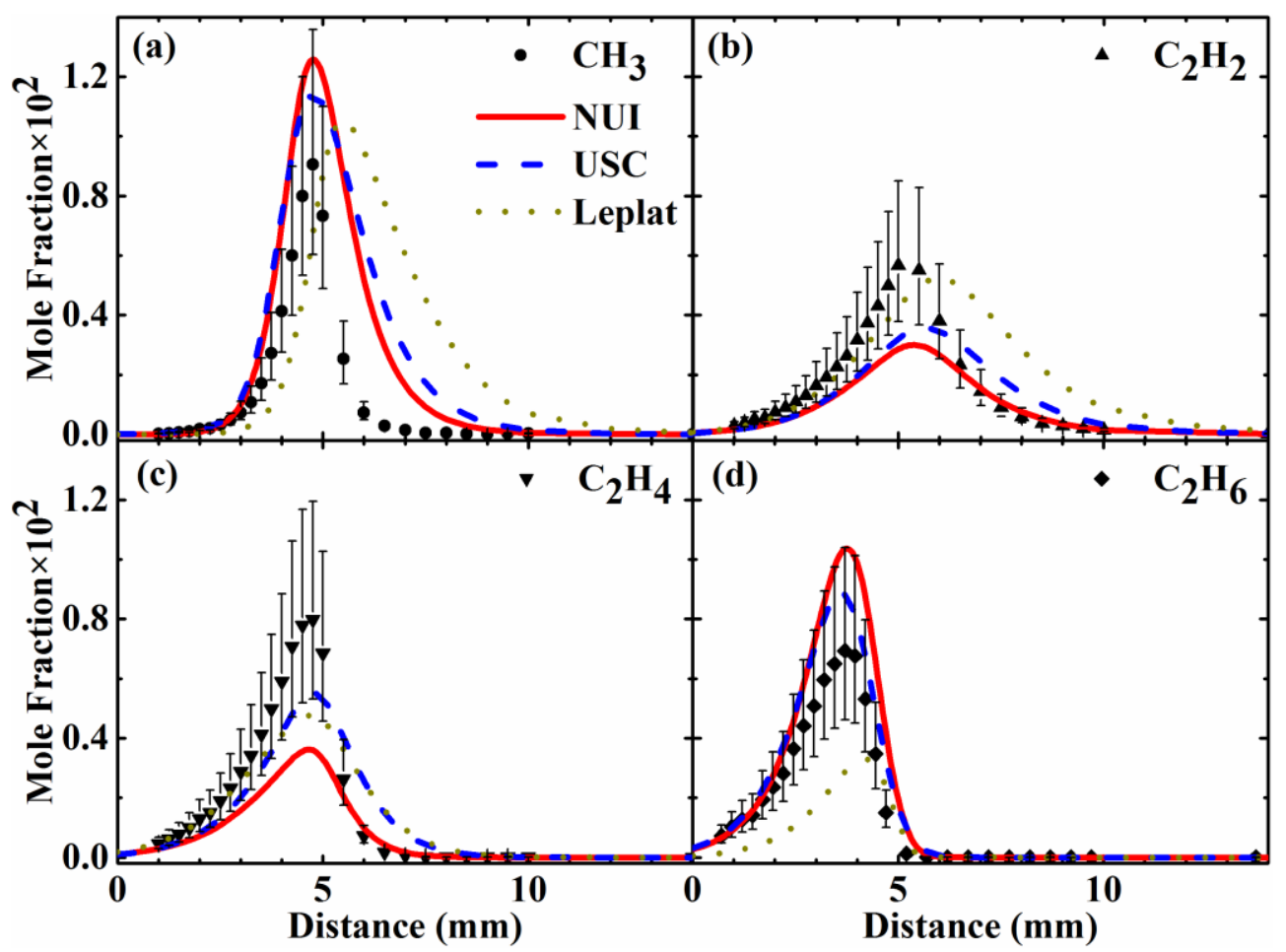

Fig. 3. Measured mole fraction profiles of $\mathrm{C}_{1} / \mathrm{C}_{2}$ hydrocarbon intermediates in the fuel-rich flame, compared with model predictions.

However, the close capture of major species and small hydrocarbons cannot guarantee a satisfactory acetaldehyde model. In Fig. 4, the ROP analysis of acetaldehyde using the three mechanisms shows that despite the fact that in all cases more than $80 \%$ acetaldehyde is consumed via $\mathrm{H}$ abstractions in the two flames, the percentages contributed from two types of $\mathrm{H}$ abstractions vary remarkably from one model prediction to another. The large difference in primary steps leads to the divergences in predicted intermediates mole fraction profiles. Thus, more analysis should be focused on related minor species, especially on oxygenated intermediates which can reveal the combustion characteristics of the fuel. 
(a) NUI

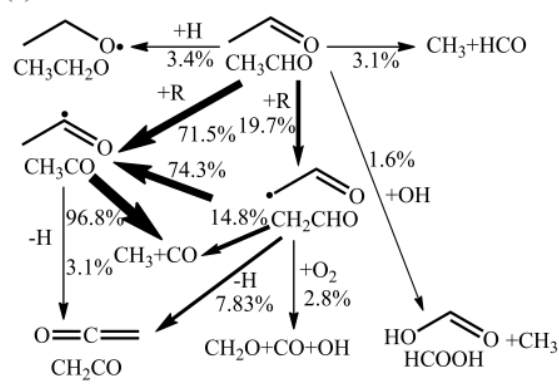

(b) USC

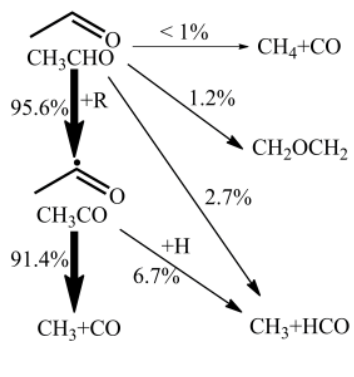

(c) Leplat

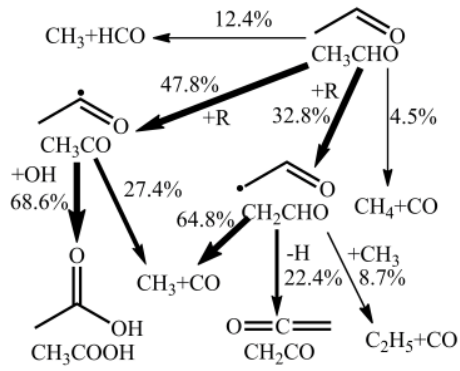

Fig. 4. Predicted fuel consumption steps of three models based on the integrated ROP analysis along the entire flame. Numbers refer to the contribution of each reaction in phi=1.7 flames.

Recognizing that the $\mathrm{C}_{2} \mathrm{H}_{3} \mathrm{O}$ isomers are the products of the $\mathrm{H}$ abstractions of $\mathrm{CH}_{3} \mathrm{CHO}$, it is interesting to distinguish and quantify these two species. Based on the measured PIE curves (Fig. S3 and S4) and the estimated PICS, their mole fraction profiles were derived with an uncertainty of a factor of 5, and compared with the model predictions for both fuel-rich and stoichiometry flames. Since the results are similar, only the comparison for the fuel-rich flame is shown in Fig. 5. It is seen that among all of the tested mechanisms, only the NUI model could reproduce the results, considering the relatively high uncertainty of experimental results.
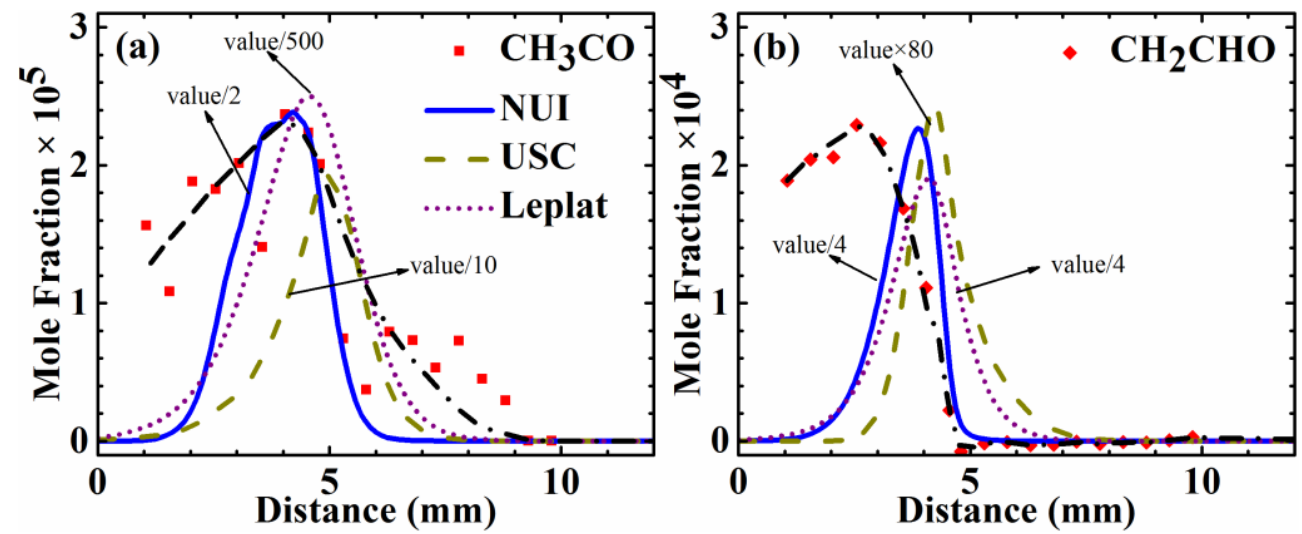

Fig. 5. Measured mole fraction profiles and model predictions for $\mathrm{CH}_{3} \mathrm{CO}$ (a) and $\mathrm{CH}_{2} \mathrm{CHO}$ (b), in the fuel-rich flame. Dash dot lines are drawn to guide the eyes.

Isomerization to ethenol $\left(\mathrm{C}_{2} \mathrm{H}_{3} \mathrm{OH}\right)$ is another pathway for $\mathrm{CH}_{3} \mathrm{CHO}$ consumption in NUI. Based on the ROP analysis with NUI, more than $90 \%$ of ethenol are produced by the isomerization of 
acetaldehyde. In Fig. 6(a), we present the experimental results and NUI prediction of ethenol. Considering the uncertainty factor of the ethenol concentration to be 1.5 , the NUI mechanism under-predicts the results, which means that improvement is still needed for the kinetic parameters of the reactions related to ethenol at the flame condition. The kinetic parameters of isomerization at low pressure in NUI from theoretical calculations [33] need further investigation.
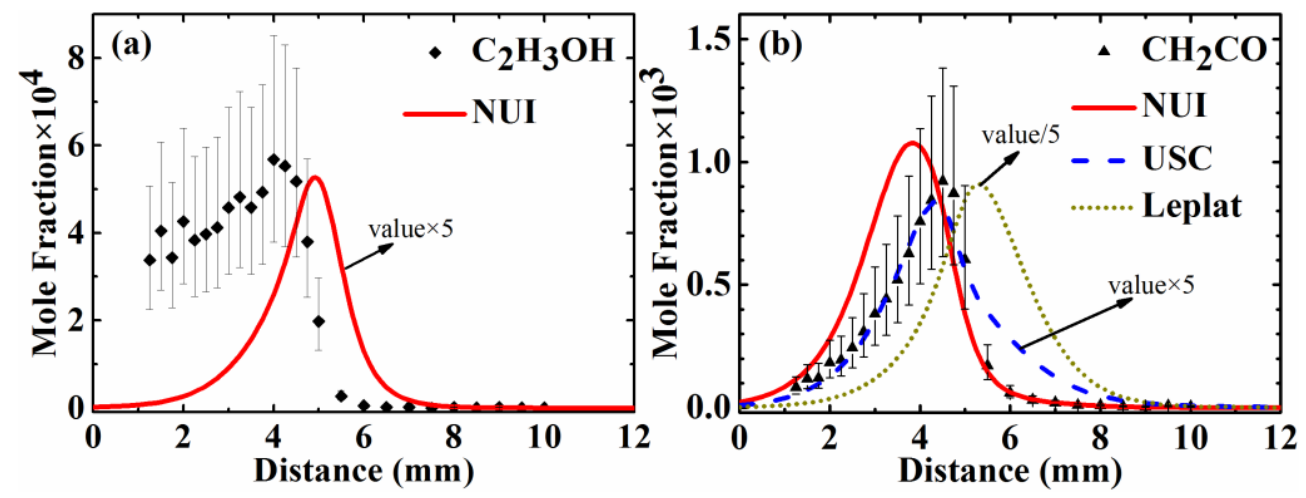

Fig. 6. Measured mole fraction profiles and model predictions for ethenol (a) and ketene (b) in the fuel-rich flame.

As illustrated in Fig. 4, ketene is an important intermediate for acetaldehyde combustion, and its peak concentration is as high as $9 \times 10^{-4}$. However, different mechanisms yield different predictions for the production pathways, even though these three mechanisms share the point that the main products of $\mathrm{CH}_{2} \mathrm{CO}$ consumption are $\mathrm{HCCO}$ and $\mathrm{CH}_{3}+\mathrm{CO}$. In NUI, the $\mathrm{H}$-abstractions of $\mathrm{CH}_{3} \mathrm{CO}$ and $\mathrm{CH}_{2} \mathrm{CHO}$ are the main contributors in the formation of $\mathrm{CH}_{2} \mathrm{CO}$, while USC predicts the principal role of $\mathrm{CH}_{3} \mathrm{CO}$ and $\mathrm{CH}_{3} \mathrm{COCH}_{3}$, and Leplat shows that $\mathrm{CH}_{2} \mathrm{CO}$ mainly comes from $\mathrm{CH}_{3} \mathrm{COOH}$ as well as $\mathrm{CH}_{3} \mathrm{CO}$ and $\mathrm{CH}_{2} \mathrm{CHO}$. The mole fraction profiles of $\mathrm{CH}_{2} \mathrm{CO}$ shown in Fig. 6(b) could help to solve this discrepancy.

As mentioned above, the significance of acetone in the ketene formation can only be predicted by USC. The ROP analysis of $\mathrm{CH}_{3} \mathrm{COCH}_{3}$ shows that the recombination of $\mathrm{CH}_{3}$ and $\mathrm{CH}_{3} \mathrm{CO}$ contributes most to the production of $\mathrm{CH}_{3} \mathrm{COCH}_{3}$, in both NUI and USC. Based on the unsatisfactory prediction of $\mathrm{CH}_{3} \mathrm{COCH}_{3}$ by these two mechanisms (Fig. 7a), the recombination 
reaction of $\mathrm{CH}_{3}$ and $\mathrm{CH}_{3} \mathrm{CO}$ needs further investigation. Acetic acid, another important species related to ketene's production in Leplat's mechanism, is not included at all in NUI or USC, despite the fact that the concentrations of $\mathrm{CH}_{3} \mathrm{COOH}$ in experiments could reach as high as $1.2 \times 10^{-4}$ for the stoichiometric flame. The non-negligible existence of $\mathrm{CH}_{3} \mathrm{COOH}$ suggests that the acetic acid and the related reactions should be included in the acetaldehyde sub-mechanism. The unsatisfactory prediction for $\mathrm{CH}_{3} \mathrm{COOH}$ in Leplat shown in Fig. $7 \mathrm{~b}$ indicates that more production or consumption pathways for $\mathrm{CH}_{3} \mathrm{COOH}$, such as the direct oxidation of $\mathrm{CH}_{3} \mathrm{CHO}$ by $\mathrm{OH}$ radicals $[34$, 35], should be added into the mechanism.
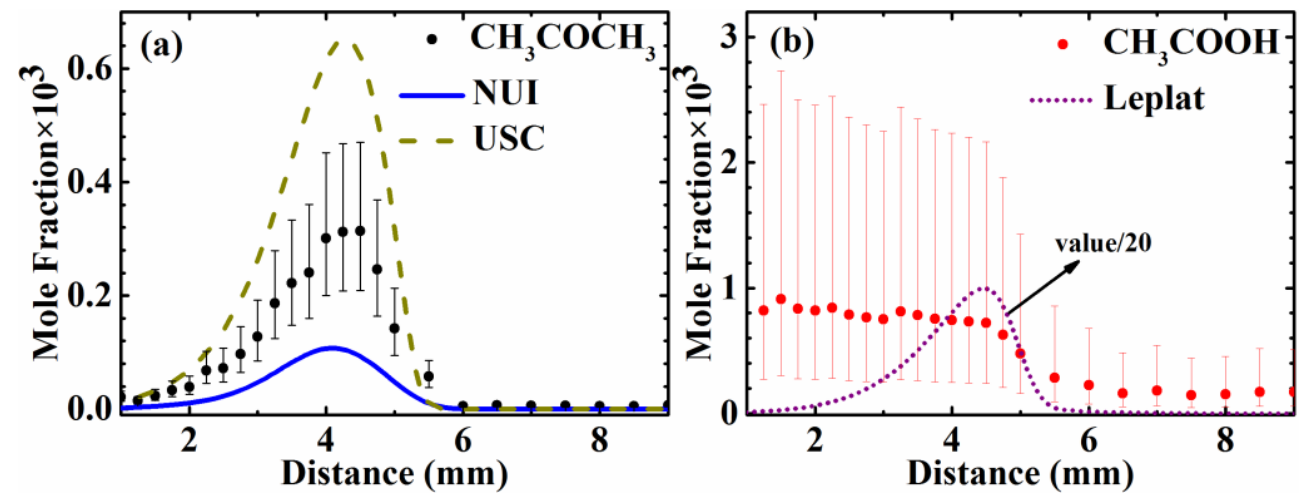

Fig. 7. Measured mole fraction profiles and model predictions for acetone (a) and acetic acid (b) in the fuel-rich flame.

Some $\mathrm{C}_{4}$ oxygenated intermediates, i.e. furan, methyl vinyl ketene, tetrahydrofuran, butanal and 1-butanol, are also identified and quantified here. Their PIE curves are presented in Fig. S5. With non-negligible concentrations, for example, the concentration of 1-butanol can be as high as $3 \times 10^{-4}$, these oxygenated species should not be ignored because their existence reveals the importance of a series of radical oxidation and recombination reactions. Nonetheless, none of the present mechanisms include these species, which requires further modeling investigation.

\section{Conclusions}


Chemical structures of two low-pressure laminar premixed acetaldehyde flames were measured by employing the synchrotron VUV radiation combined with MBMS techniques. Several species were observed for the first time in acetaldehyde flames. Though acetaldehyde reactions are included in the three mechanisms including NUI, USC and Laplat, none of them can well reproduce the mole fraction profiles of the intermediates and their predictions are not consistent for most species. Ketene is supposed to be a crucial intermediate in acetaldehyde flames, to which these models yield totally different mole fraction predictions and ROP analysis results. The detection of some oxygenated intermediates shed light on chemistry details which were ignored in previous studies. $\mathrm{CH}_{3} \mathrm{COOH}$, $\mathrm{CH}_{3} \mathrm{COCH}_{3}$ and some $\mathrm{C}_{4}$ oxygenated intermediates are all of non-negligible fractions but are not well predicted, indicating that reaction classes such as radical oxidation and radical recombination in $\mathrm{CH}_{3} \mathrm{CHO}$ combustion might be ignored in previous studies. The species mole fraction profiles provide valuable information that should guide the development of future acetaldehyde sub-mechanisms for the $\mathrm{C} 0-\mathrm{C} 4$ core mechanisms.

\section{Acknowledgements}

This work is supported by the Natural Science Foundation of China (51306102, U1332208). NH and KM are supported by the U.S. Department of Energy (USDOE), Office of Basic Energy Sciences (BES) under Grant No. DE-AC04-94-AL85000. We thank the expert technical assistance of Paul Fugazzi. The Advanced Light Source is supported by the Director, Office of Science, BES, USDOE under Contract No. DE-AC02-05CH11231. Sandia is a multi-program laboratory operated by Sandia Corporation, a Lockheed Martin Company, for the National Nuclear Security Administration under contract DE-AC04-94-AL85000. 


\section{References:}

[1] P. Oßwald, H. Güldenberg, K. Kohse-Höinghaus, B. Yang, T. Yuan, F. Qi, Combust. Flame 158 (1) (2011) 2-15.

[2] S.M. Sarathy, P. Oßwald, N. Hansen, K. Kohse-Höinghaus, Prog. Energ. Combust. 44 (2014) 40-102.

[3] R.D. Kern, H.J. Singh, K. Xie, Aip. Conf. Proc. 208 (1990) 487-492.

[4] K.S. Gupte, J.H. Kiefer, R.S. Tranter, S.J. Klippenstein, L.B. Harding, Proc. Combust. Inst. 31 (1) (2007) 167-174.

[5] S.J. Won, J.C. Ryu, J.H. Bae, Y.D. Kim, J.G. Kang, B. Kor. Chem. Soc. 21 (5) (2000) 487-492.

[6] K. Yasunaga, S. Kubo, H. Hoshikawa, T. Kamesawa, Y. Hidaka, Int. J. Chem. Kinet. 40 (2) (2008) 73-102.

[7] M. Christensen, M.T. Abebe, E.J.K. Nilsson, A.A. Konnov, Proc. Combust. Inst. 35 (1) (2015) 499-506.

[8] P. Dagaut, M. Reuillon, D. Voisin, M. Cathonnet, M. McGuinness, J.M. Simmie, Combust. Sci. Technol. 107 (4-6) (1995) 301-316.

[9] N. Leplat, J. Vandooren, Combust. Sci. Technol. 182 (2010) 436-448.

[10] N.M. Marinov, Int. J. Chem. Kinet. 31 (3) (1999) 183-220.

[11] W.K. Metcalfe, S.M. Burke, S.S. Ahmed, H.J. Curran, Int. J. Chem. Kinet. 45 (10) (2013) 638-675.

[12] H. Wang, X. You, A.V. Joshi, S.G. Davis, A. Laskin, F. Egolfopoulos, C.K. Law, (2007) http://ignis.usc.edu/USC_Mech_II.htm, May 2007. 
[13] T.A. Cool, A. McIlroy, F. Qi, P.R. Westmoreland, L. Poisson, D.S. Peterka, M. Ahmed, Rev. Sci. Instrum. 76 (2005) 094102.

[14] N. Hansen, M. Braun-Unkhoff, T. Kathrotia, A. Lucassen, B. Yang, Proc. Combust. Inst. 35 (1) (2015) 771-778.

[15] B. Yang, P. Oßwald, Y. Li, J. Wang, L. Wei, Z. Tian, F. Qi, K. Kohse-Höinghaus, Combust. Flame 148 (4) (2007) 198-209.

[16] T.A. Cool, K. Nakajima, C.A. Taatjes, A. McIlroy, P.R. Westmoreland, M.E. Law, A. Morel, Proc. Combust. Inst. 30 (1) (2005) 1681-1688.

[17] A. Lucassen, N. Labbe, P.R. Westmoreland, K. Kohse-Höinghaus, Combust. Flame 158 (9) (2011) 1647-1666.

[18] M. Schenk, L. Leon, K. Moshammer, P. Oßwald, T. Zeuch, L. Seidel, F. Mauss, K. Kohse-Höinghaus, Combust. Flame 160 (3) (2013) 487-503.

[19] N. Hansen, M.R. Harper, W.H. Green, Phys. Chem. Chem. Phys. 13 (45) (2011) 20262-20274. [20] S. Dooley, F.L. Dryer, B. Yang, J. Wang, T.A. Cool, T. Kasper, N. Hansen, Combust. Flame 158 (4) (2011) 732-741.

[21] J.D. Savee, S. Soorkia, O. Welz, T.M. Selby, C.A. Taatjes, D.L. Osborn, J. Chem. Phys. 136 (2012) 134307.

[22] J. Wang, B. Yang, T.A. Cool, N. Hansen, T. Kasper, Int. J. Mass Spectrom. 269 (3) (2008) 210-220.

[23] T.A. Cool, J. Wang, K. Nakajima, C.A. Taatjes, A. Mcllroy, Int. J. Mass Spectrom. 247 (1-3) (2005) 18-27.

[24] J. Wang, L. Wei, B. Yang, R. Yang, C. Huang, X. Shan, L. Sheng, Y. Zhang, F. Qi, C. Yao, Q. 
Li, Q. Ji, Chem. Res. Chinese U. 22 (3) (2006) 375-378.

[25] G. Cooper, J.E. Anderson, C.E. Brion, Chem. Phys. 209 (1) (1996) 61-77.

[26] T.A. Cool, K. Nakajima, T.A. Mostefaoui, F. Qi, A. McIlroy, P.R. Westmoreland, M.E. Law, L. Poisson, D.S. Peterka, M. Ahmed, J. Chem. Phys. 119 (16) (2003) 8356.

[27] B. Yang, J. Wang, T.A. Cool, N. Hansen, S. Skeen, D.L. Osborn, Int. J. Mass Spectrom. 309 (2012) 118-128.

[28] N. Hansen, S.J. Klippenstein, J.A. Miller, J. Wang, T.A. Cool, M.E. Law, P.R. Westmoreland, T. Kasper, K. Kohse-Höinghaus, J. Phys. Chem. A 110(13) (2006) 4376-4388.

[29] M. Xie, Z. Zhou, Z. Wang, D. Chen, F. Qi, Int. J. Mass Spectrom. 293 (1-3) (2010) 28-33.

[30] U. Struckmeier, P. Oßwald, T. Kasper, L. Böehling, M. Heusing, M. Köhler, A. Brockhinke, K. Kohse-Höinghaus, Z. Phys. Chem. 223 (4-5) (2009) 503-537.

[31] F.N. Egolfopoulos, N. Hansen, Y. Ju, K. Kohse-Höinghaus, C.K. Law, F. Qi, Prog. Energ. Combust. 43 (2014) 36-67.

[32] R.J. Kee, F.M. Rupley, J.A. Miller, Inc., San Diego, CA (2008)

[33] J. Shao, C. Gong, X. Li, J. Li, Theor. Chem. Acc. 128 (3) (2011) 341-348.

[34] M. Li, J.S. Zhang, W. Shen, Q.X. Meng, Chinese J. Chem. 22 (8) (2004) 792-797.

[35] A. Jalan, I.M. Alecu, R. Meana-Pañeda, J. Aguilera-Iparraguirre, K.R. Yang, S.S. Merchant, D.G. Truhlar, W.H. Green, J. Am. Chem. Soc. 135 (30) (2013) 11100-11114. 


\section{Figure Captions}

Fig. 1. Model predictions using AramcoMech1.3 with the perturbed temperature profiles $( \pm 150 \mathrm{~K})$ in fuel-rich acetaldehyde flame. Filled areas represent effect of temperature uncertainties on modeling computations.

Fig. 2. Measured mole fraction profiles (symbols) of major species in two flames, compared with predictions from NUI (lines).

Fig. 3. Measured mole fraction profiles of $C_{1} / C_{2}$ hydrocarbon intermediates in the fuel-rich flame, compared with model predictions.

Fig. 4. Predicted fuel consumption steps of three models based on the integrated ROP analysis along the entire flame. Numbers refer to the contribution of each reaction in phi=1.7 flames.

Fig. 5. Measured mole fraction profiles and model predictions for $\mathrm{CH}_{3} \mathrm{CO}$ (a) and $\mathrm{CH}_{2} \mathrm{CHO}$ (b), in the fuel-rich flame. Dash dot lines are drawn to guide the eyes.

Fig. 6. Measured mole fraction profiles and model predictions for ethenol (a) and ketene (b) in the fuel-rich flame.

Fig. 7. Measured mole fraction profiles and model predictions for acetone (a) and acetic acid (b) in the fuel-rich flame. 